Check for updates

Cite this: RSC Adv., 2019, 9, 22531

\title{
Utilization of metabolic energy in treatment of ocular surface disorders: polyphosphate as an energy source for corneal epithelial cell proliferation
}

Adrian Gericke, ${ }^{a}$ Xiaohong Wang, (DD *b Maximilian Ackermann, ${ }^{c}$ Meik Neufurth, ${ }^{b}$ Matthias Wiens, ${ }^{b}$ Heinz C. Schröder, ${ }^{b}$ Norbert Pfeiffer ${ }^{a}$ and Werner E. G. Müller (D)*b

Impaired regeneration of the corneal epithelium, as found in many ocular surface diseases, is a major clinical problem in ophthalmology. We hypothesized that corneal epithelial regeneration can be promoted by the physiological, energy-delivering as well as "morphogenetically active" polymer, inorganic polyphosphate (polyP). Corneal limbal explants (diameter, $4 \mathrm{~mm}$ ) were cultivated on collagen-coated well plates in the absence or presence of polyP (chain length, $\sim 40 \mathrm{P}_{\mathrm{i}}$ units; $50 \mu \mathrm{g} \mathrm{ml}^{-1}$ ) or human platelet lysate (hplysate; $5 \% \mathrm{v} / \mathrm{v}$ ). Cell outgrowth and differentiation were analyzed after staining with DRAQ5 (nuclei) and rhodamine phalloidin (cytoskeleton), as well as by environmental scanning electron microscopy (ESEM). Cell growth/viability of hCECs was assessed by XTT assay. The expression of SDF-1 was quantitated by qRT-PCR. Exposure to hp-lysate (also containing polyP) increased cell migration already at day 1 . Even stronger was the effect of polyP. This effect was blocked by a mast cell serine protease. The formation of cell multilayers was enhanced by hp-lysate or even more by polyP. ESEM revealed continuous cell junctions and prominent microvilli on the surface of adjacent cells exposed to polyP; those structures were only rarely seen in the controls. The hp-lysate and, more potently, polyP increased the proliferation of hCECs, as well as SDF-1 expression. The findings indicate the potential usefulness of the natural polymer, polyP, for topical treatment of corneal epithelial defects. Future studies are directed to develop suitable formulations of polyP, such as biomimetic polyP nano/microparticles showing an adjustable release kinetics.

Received 12th June 2019

Accepted 16th July 2019

DOI: $10.1039 / c 9 r a 04409 d$

rsc.li/rsc-advances

\section{Introduction}

The corneal epithelium acts as a barrier against the environment and is critically important for maintaining corneal transparency. The human corneal epithelium is $50 \mu \mathrm{m}$ thick and composed of five to seven layers of regularly stratified squamous non-keratinized cells. ${ }^{1}$ Regeneration of the corneal epithelium is driven by stem and transient amplifying cells, the only cells with proliferative potential. According to the XYZ hypothesis, the limbus functions as a reservoir of ocular stem cells. Driven by asymmetric division, these stem cells remain within the limbus from where transient amplifying cells (TACs)

\footnotetext{
${ }^{a}$ Department of Ophthalmology, University Medical Center of the Johannes Gutenberg-University Mainz, Langenbeckstrasse 1, 55131 Mainz, Germany

${ }^{b} E R C$ Advanced Investigator Grant Research Group at the Institute for Physiological Chemistry, University Medical Center of the Johannes Gutenberg University, Duesbergweg 6, D-55128 Mainz, Germany. E-mail: wmueller@uni-mainz.de; wang013@uni-mainz.de; Fax: +49-6131-39-25243; Tel: +49-6131-39-25910

'Institute of Functional and Clinical Anatomy, University Medical Center of the Johannes Gutenberg University, Johann Joachim Becher Weg 13, 55099 Mainz, Germany
}

migrate centripetally and anteriorly. During this phase, the TACs progressively undergo proliferation during which they lose "stemness". ${ }^{2}$ Later, corneal epithelial cells differentiate from columnar basal cells, via wing cells, to squamous cells. Proliferation, migration, growth, differentiation and apoptosis are regulated by growth factors, neuropeptides, catecholamines, cytokines, vitamins, extracellular matrix molecules, nutrients, electrolytes, and oxygen, which are modulated by environmental factors. ${ }^{3,4}$ In many ocular surface diseases, including limbal stem cell deficiency (LSCD), diabetic keratopathy, dry eye disease, and neurotrophic keratopathy, regeneration of the corneal epithelium is compromised, which remains a still unresolved major clinical problem. ${ }^{5}$

In our group, we focused on the development of a new approach in regenerative medicine by applying a physiological inorganic polymer, present in all cells and also extracellularly, for the reconstitution and the support of damaged regions in the body with both somatic cells, such as fibroblasts, and adult stem cells, like mesenchymal stem cells (reviewed in: ref. 6-8). It is the polyphosphate (polyP) that is a linear inorganic polymer consisting of orthophosphate linked by high-energy 
phosphoanhydride bonds (reviewed in: ref. 9). The average chain length of polyP in mammalian tissue is $\approx 20$ to 100 phosphate units. The distinguished characteristics of polyP is to be capable of inducing proliferation and differentiation of bone cells or stem cells through differential gene expression ("morphogenetic activity"). Exceptional is the property of this biopolymer to deliver high-energy phosphate both into the extracellular space to promote anabolic processes, like extracellular matrix synthesis, and into the cells; ${ }^{10}$ reviewed in: ref. 8 . Since the polymer can be fabricated as nano-/microparticles, ${ }^{\mathbf{1 1}}$ like present in the cells e.g. blood platelets, and be converted to the coacervate state, ${ }^{12}$ polyP can be applied as hardenable bioinks, applicable in additive manufacturing/3D printing and $3 \mathrm{D}$ cell bioprinting, and also for the encapsulation of stem cells. Finally, it is to mention that polyP is one major component in blood platelets that contributes to the morphogenetic activity of the growth factors in these cells. ${ }^{13}$ In addition, polyP was found to attract mesenchymal stem cells most likely via upregulation of the expression of the gene encoding the stromal cell-derived factor-1a (SDF-1), ${ }^{14}$ an attracting chemokine elicited ubiquitously in many tissues and cell types. ${ }^{15}$

Based on the finding that platelets also contribute with their growth factors to regeneration processes of ocular surface diseases, ${ }^{\mathbf{1 6 - 1 8}}$ it was tempting to determine the epitheliotropic potential of the major polymeric, inorganic constituent of the blood platelets, polyP, with respect to migration and proliferation of limbal explant cultures and of commercially available human corneal epithelial cells (hCECs).

\section{Material and methods}

\section{Materials}

Na-polyphosphate (Na-polyP) with an average chain length of 40 phosphate units $\left(\mathrm{P}_{\mathrm{i}}: 40\right)$ has been purchased from Chemische Fabrik Budenheim (Budenheim; Germany).

\section{Cell culture of human corneal epithelial cells}

For cultures of human corneal epithelial cells, corneo-scleral donor buttons were used, as previously described. ${ }^{19}$ The use of donor tissue has been consented for transplantation and research and obtained from the eye bank of RhinelandPalatinate (Mainz; Germany); ethical approval under the appl.number 837.390.07 (5925). Under sterile conditions, round tissue samples (diameter of $4 \mathrm{~mm}$ ) were excised from the corneo-scleral rims $(\sim 2 \mathrm{~mm}$ of the peripheral cornea and $\sim 2 \mathrm{~mm}$ of the limbus) with a disposable biopsy punch (pfm medical, Köln; Germany). The tissue samples were transferred to collagen I-coated 24-well plates (\#A1142802; Thermo Fisher Scientific, Dreieich; Germany) and incubated in Epithelial Cell Media (PromoCell, Heidelberg; Germany), as described by the manufacturer, at $37{ }^{\circ} \mathrm{C}$ under $5 \% \mathrm{CO}_{2} / 95 \%$ air atmosphere. Initially, the cells were incubated with the complete media; every $2 \mathrm{~d}$ the medium was changed. Every second day fresh supplemented medium was added to the cultures. Where indicated, either Na-polyP was added at a concentration of $50 \mu \mathrm{g}$ $\mathrm{ml}^{-1}$ together with $1 \mathrm{mM}$ calcium chloride dihydrate (\#1.02382
EMD Millipore; Sigma, Taufkirchen; Germany), or 5\% (v/v) PLTMax human platelet lysate [hp-lysate] (Cat. \#SCM141; Merck) was added. $\mathrm{CaCl}_{2}$ had to be added to the polyP in order to compensate for the chelating activity of polyP for $\mathrm{Ca}^{2+} \cdot{ }^{20}$

In parallel, experiments were performed with commercially available human corneal epithelial cells (hCECs) cultivated at passage 3 to 8 . The cells were obtained from Merck/Millipore (\#SCCE016; Merck Darmstadt; Germany) and cultivated in the same way and with the same medium as the epithelial cells from the limbal explants.

\section{Measurement of the outgrowth rate from limbal explants}

A semiquantitative assessment of the outgrowth rate was performed as described earlier. ${ }^{21}$ The explants were inspected every day by phase contrast microscopy. The increase of cells in the visual field was recorded using an ocular micrometer. The leading rims of the cell masses were recorded. Surely this value reflects not only migration but also growth/proliferation of the cells; however, migration is considered as the major factor.

Where indicated, the migration was inhibited by addition of human chymase (C8118; Sigma-Aldrich) at a concentration of $10 \mu$ units per $\mathrm{ml}$ as described. ${ }^{22}$

\section{Presence of polyP in human platelet lysate}

For the isolation of polyP from human platelet lysate (hp-lysate), the organic solvent extraction procedure was applied. ${ }^{23} \mathrm{hp}$ lysate $(10 \mathrm{ml})$ was added to $5 \mathrm{ml}$ of $24: 1(\mathrm{v} / \mathrm{v})$ chloroform : isoamyl alcohol solution and shaken for $30 \mathrm{~min}$. The polyP was collected in the aqueous supernatant after centrifugation. This material was freeze-dried and finally suspended in $0.5 \mathrm{ml}$ of distilled water. Aliquots of $20 \mu \mathrm{l}$ were taken and applied onto urea/polyacrylamide gels and analyzed as described. ${ }^{24}$ The gels were stained with toluidine blue. ${ }^{25}$ The size markers polyP $\mathrm{P}_{40}$ (Chemische Fabrik Budenheim) and $\mathrm{Na}$ hexametaphosphate (\#30553 Sigma; Na-polyP ${ }_{6}$ ) were run in parallel.

\section{Microscopic analysis}

The ESEM (environmental scanning electron microscope) studies were performed with the ESEM XL-30 machine (Philips, Eindhoven; Netherlands) as outlined. ${ }^{26}$ For these ESEM inspections, the cells were transferred into $2 \%[\mathrm{v} / \mathrm{v}]$ aqueous glutaraldehyde fixative, fixated in osmium tetroxide, processed through acetone dehydration steps and finally critical point dried at $43{ }^{\circ} \mathrm{C}$, as described. ${ }^{27}$

\section{Staining with DRAQ5 and rhodamine/phalloidin}

The samples were stained with DRAQ5 (1:1000 diluted; Thermo Fisher Scientific, Dreieich; Germany) and rhodamine phalloidin (1:70; Invitrogen/Thermo Fisher Scientific) as described. ${ }^{28}$ At first, the cells were fixed in $4 \%$ paraformaldehyde solution. After PBS (phosphate-buffered saline) rinsing, the samples were permeabilized by immersion in acetone for $20 \mathrm{~min}$ at $-20{ }^{\circ} \mathrm{C}$. Subsequently the unspecific binding sites were blocked by incubating the samples in $0.3 \%$ 
bovine serum albumin for $30 \mathrm{~min}$ at room temperature. Then, the samples were washed three times in PBS and subsequently stained with rhodamine phalloidin to visualize the cytoskeleton. The nuclei were stained with DRAQ5 and the specimens were inspected with an Evos FL epifluorescence microscope (Thermo Fisher Scientific).

\section{Cell proliferation/viability assay}

The assays were performed with the proliferation/viability assay based on XTT (2,3-bis-(2-methoxy-4-nitro-5-sulfophenyl)-2Htetrazolium-5-carboxanilide); the Cell Proliferation Kit II from Roche (Mannheim; Germany) was used, as outlined. ${ }^{29}$ The absorbance was determined at $450 \mathrm{~nm}$ and the values were subtracted by the background values $(500 \mathrm{~nm})$. The cells were incubated for up to $3 \mathrm{~d}$. Ten parallel experiments were performed.

\section{Quantitative real-time polymerase chain reaction (qRT-PCR)}

The hCECs were plated onto 24-well tissue culture plates and incubated for a period of up to $6 \mathrm{~d}$ in human ocular epithelia complete medium in the absence of any additional component or in the presence of $5 \%(\mathrm{v} / \mathrm{v}) \mathrm{hp}$-lysate, or $50 \mu \mathrm{g} \mathrm{ml} \mathrm{m}^{-1} \mathrm{Na}$-polyP in the presence of $1 \mathrm{mM} \mathrm{CaCl}_{2}$ for $3 \mathrm{~d}$ or $6 \mathrm{~d}$ in $5 \% \mathrm{CO}_{2} / 95 \%$ air atmosphere; every $2 \mathrm{~d}$ the medium was changed. Subsequently, quantitative real-time polymerase chain reactions (qRT-PCR) were performed with $\sim 5 \mu \mathrm{g}$ of total RNA in the PCR reaction mixtures of $40 \mu \mathrm{l}$ and using the iCycler (Bio-Rad, Hercules; CA); $1 / 10$ serial dilutions were performed in triplicate. The reactions were run using temperature cycles as described before ${ }^{30}$ and following the protocol recommended by the manufacturer. The procedure included an initial denaturation at $95{ }^{\circ} \mathrm{C}$ for $10 \mathrm{~min}$, followed by a 30-cycle amplification consisting of denaturation at $94{ }^{\circ} \mathrm{C}$ for $15 \mathrm{~s}$, annealing at $55{ }^{\circ} \mathrm{C}$ for $30 \mathrm{~s}$ and extension at $72{ }^{\circ} \mathrm{C}$ for $30 \mathrm{~s}$. The following primer pair was used for the human stromal cell-derived factor $1 \alpha$ (SDF-1; accession number: AY874118 (ref. 31)) Fwd: 5'-AGAGCCAACGTCAAGCATCT- ${ }^{\prime}$ and Rev: $5^{\prime}$-GGGCAGCCTTTCTCTTCTTC-3'. As reference, the expression of the human GAPDH gene was used (glyceraldehyde 3-phosphate dehydrogenase; NM_002046.3) Fwd: $5^{\prime}$-CCGTCTAGAAAAACCTGCC-3' and Rev: $5^{\prime}$ GCCAAATTCGTTGTCATACC- $3^{\prime}$. The threshold position was set to 50.0 relative fluorescence units above PCR subtracted baseline for all runs. The mean $C_{\mathrm{t}}$ values and efficiencies were calculated by the iCycler software (Bio-Rad). The estimated PCR efficiencies were in the range 93-103\%. Expression levels of the respective transcripts were correlated to the reference gene $G A P D H$ as described. ${ }^{32}$

\section{Statistical analysis}

After verification that the respective values follow a standard normal Gaussian distribution and that the variances of the respective groups are equal, the results were statistically assessed using the independent two-sample Student's $t$-test. ${ }^{33}$

\section{Results}

\section{Corneal limbal explants}

Corneal limbal explants were obtained by punching out spherical explants (diameter of $4 \mathrm{~mm}$ ) from corneo-scleral rims, comprising the limbus region (Fig. 1A and B). The samples were subsequently turned around to allow the attachment of the epithelium to collagen-coated 24-well plates (Fig. 1C). In order to prevent a floating away the explants were hold fast with a small stainless steel weight of $0.3 \mathrm{~g}$. At the beginning of cultivation of the explants in human ocular epithelia complete medium as described under "Material and methods", no cells are found to be present outside the corneal limbal explant sample (Fig. 1D).

\section{Presence of polyP in human platelet lysate}

From earlier studies it is known that hp-lysate contains polyP with a chain length of 60 to $90 \mathrm{P}_{\mathrm{i}}$ units. $^{34}$ This result was confirmed here by showing that hp-lysate, after extraction with chloroform : isoamyl alcohol contains polyP between 40 and 65 $\mathrm{P}_{\mathrm{i}}$ units (Fig. 2).

\section{Effect of polyP on epithelial outgrowth: migration}

Corneal limbal explants are suitable to study the dynamics and the migration of epithelial cells. ${ }^{35}$ The speed of migration of the cells in the present study is comparably high if compared to earlier studies ${ }^{35}$ where it has been shown that a lag phase of 4 to $5 \mathrm{~d}$ exists. However,
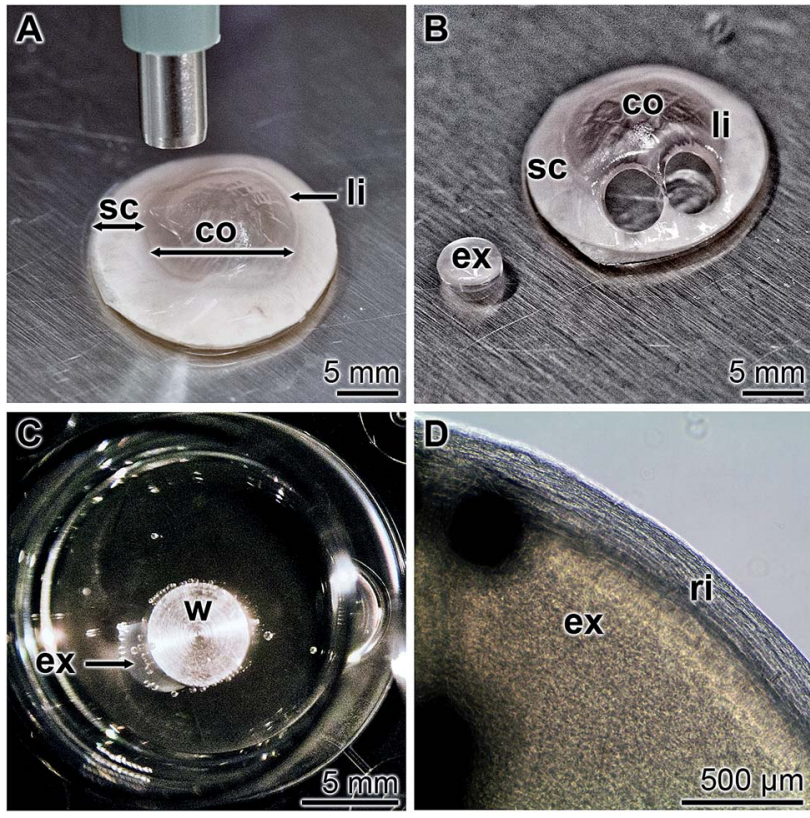

Fig. 1 Preparation of human corneal limbal explants. (A and B) Spherical samples from the corneo-scleral rims were withdrawn from with a biopsy punch at the rim between the sclera (sc) and the cornea (co), including also the limbus (li). (C) The explants (ex) obtained were turned around and attached to the bottom of the collagen-coated 24well plates. The samples were slightly fixed with a stainless steel weight (w). (D) After this procedure no cells were found outside of the rim (ri) of the explants. 


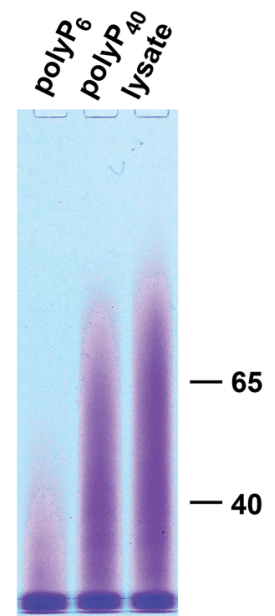

Fig. 2 Identification of polyP in hp-lysate by organic-water extraction and subsequent size separation by urea/polyacrylamide gel electrophoresis; the gels were stained with toluidine blue. The size markers of poly $\mathrm{P}_{6}$ and poly $\mathrm{P}_{40}$ were run in parallel. The most intense staining was found in the hp-lysate polyP at an apparent chain length between 40 and $65 \mathrm{P}_{\mathrm{i}}$ units.

also in recent analyses a faster start of the migration of about 10$15 \mathrm{~h}$ has been achieved. ${ }^{36}$ In our studies no cells were present outside of the explant at time zero (Fig. 3A). Likewise, no cells exist outside the explants under control conditions, in the absence of hplysate or polyP, during the first $1 \mathrm{~d}$ (Fig. 3B). Only a small border of cells is seen at day 2 and day 3 (Fig. 3E and $\mathrm{H}$ ). In contrast, after addition of hp-lysate $(5 \%[\mathrm{v} / \mathrm{v}])$ to the human ocular epithelia complete medium, substantial increase of the cell density around the explants is seen already at day 1 , which becomes more massive after $2 \mathrm{~d}$ and $3 \mathrm{~d}$ (Fig. 3C, F and I). Even stronger and more voluminous are the cells which migrated out of the explants after addition of $50 \mu \mathrm{g} \mathrm{ml}^{-1}$ of Na-polyP (Fig. 3D, G and J). The outgrowth of the cells occurs in multilayers.

Chymase, a mast cell serine protease modulating the activity of matrix metalloproteases, ${ }^{37}$ has been described to inhibit migration of corneal epithelial cells. ${ }^{38}$ This enzyme was added also to the explants in the present study, and a strong inhibition is seen especially at day 3 during the incubation period, both in the presence of polyP or of hp-lysate (Fig. 4). An almost complete blockade of the outgrowth is seen in all three assays.

\section{Staining pattern of the epithelial cells with DRAQ5 and rhodamine/phalloidin}

The samples were stained with DRAQ5 and rhodamine/phalloidin to highlight the complex actin filament bundle dynamics of corneal epithelial cell layers that had been formed during the migration of the cells from the explants. Already the DRAQ5 stained samples disclose that the cells, migrated out or pushed out from the explants, form after $3 \mathrm{~d}$ a multilayered rim (Fig. 5A-C), irrespective of the presence of hp-lysate or of polyP in the incubation assay. If the cells were stained with rhodamine/phalloidin, the multilayered arrangement of the cells becomes even more prominent (Fig. 5D-F). These images also support an intimate association of the cells within the outgrown rim.

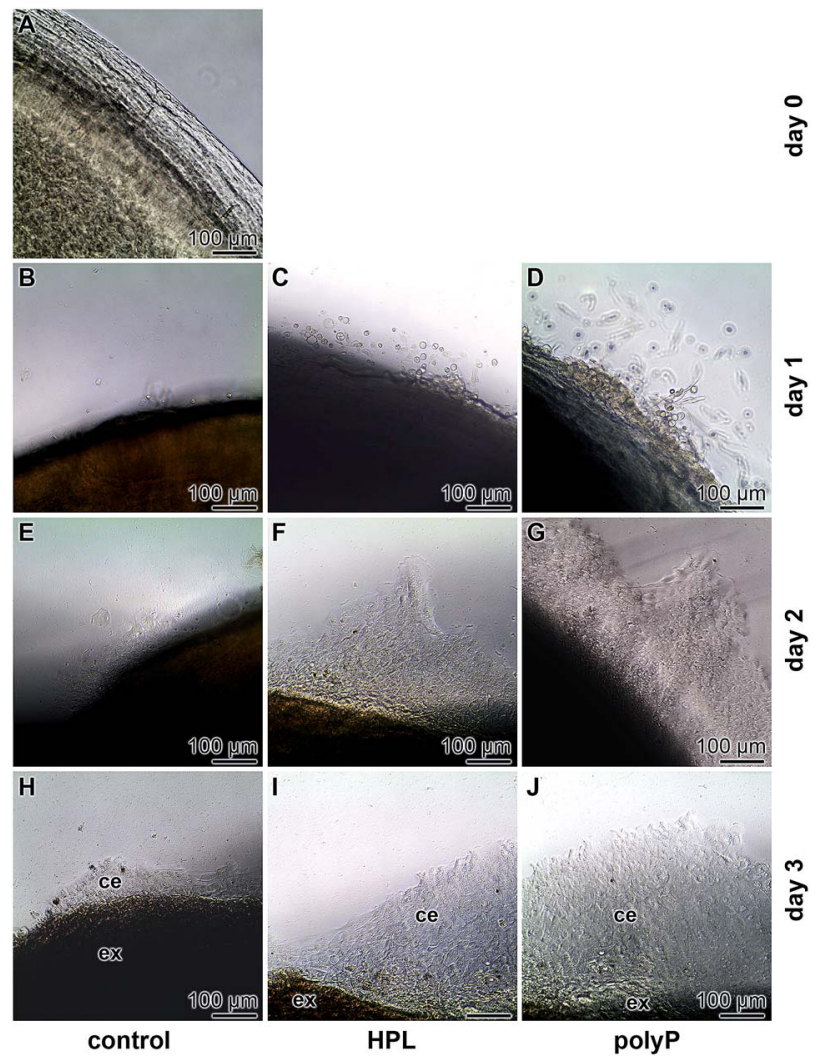

Fig. 3 Outgrowth of epithelial cells from corneo-scleral explants (ex). (A) At day 0 no cells could be seen in the surrounding of the explants. ( $B, E$ and $H$ ) Kinetics of outgrowth in the controls, in which no hplysate (HPL) or polyP had been added during the $3 \mathrm{~d}$ incubation period. In contrast, in the assays which had been supplemented either with (C, F and I) hp-lysate (HPL) or with (D, G and J) polyP an increasing amount of cells (ce) could be visualized.

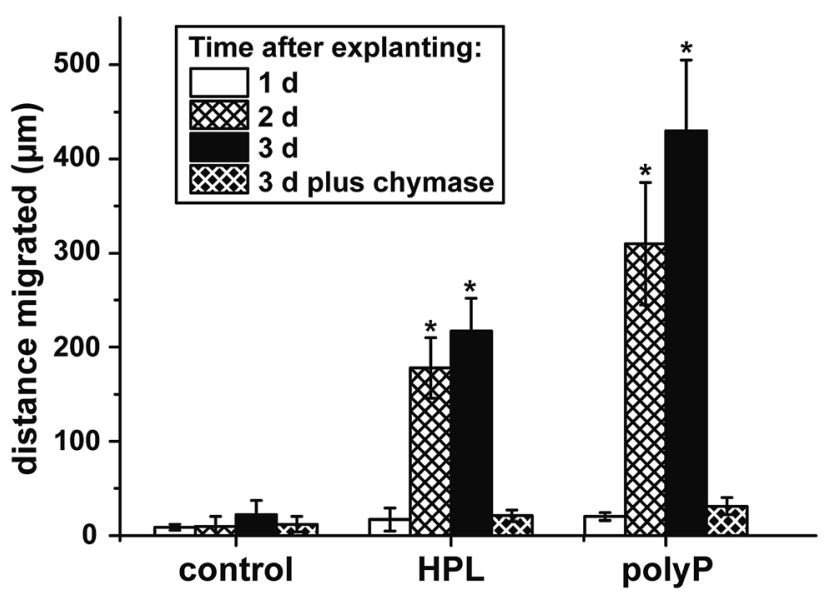

Fig. 4 Increase of cells around the explants in control assay or in samples supplemented with hp-lysate (HPL) or polyP. In addition, in the $3 \mathrm{~d}$ 's experiments the three different explant series were exposed to chymase during the complete incubation period, as described under "Material and methods". Values are means \pm SEM coming from 7 parallel experiments. (*) Significance levels between the migration distances of cells from the HPL or the polyP treated explants and the corresponding controls are marked $(P<0.01)$. 


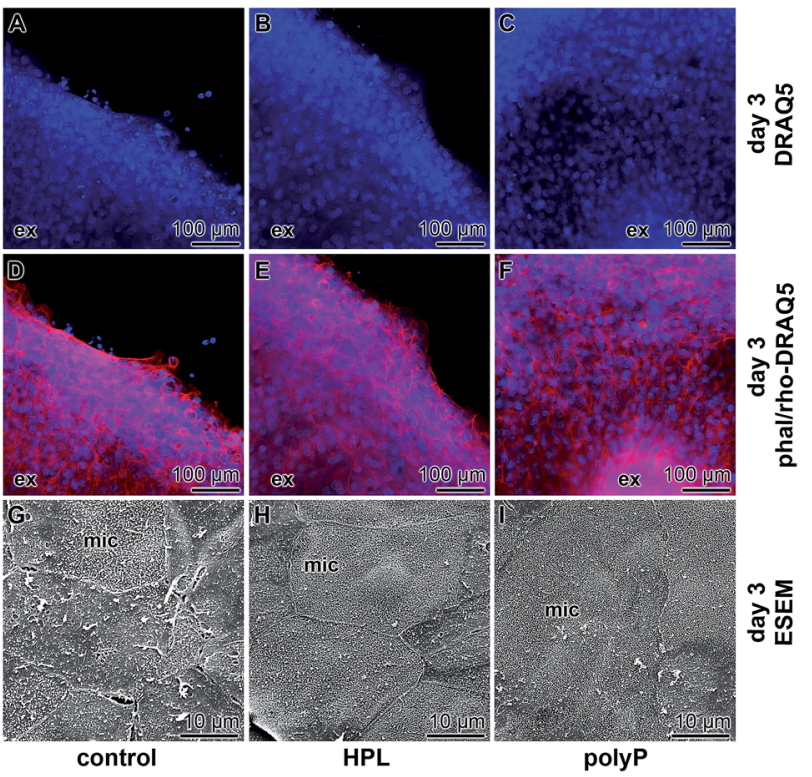

Fig. 5 Immunofluorescence and ESEM analysis of the outgrown cells, $3 \mathrm{~d}$ after initiating of the assays. In the first series the cell layers outgrown from the explants (ex) were stained with (A-C) DRAQ5 to identify the nuclei or double-stained with (D-F) rhodamine/phalloidin and DRAQ5 to express the complex multilayered arrangement of the cells migrated out from the explants; immunofluorescence light microscopy. The rim of the explant is highlighted (ex). In (G-l) higher magnification images of the epithelial cells showing the different degrees of differentiation of the cells; ESEM. In the controls (G) the cells are not continuously attached to each other with cell-to-cell junctions. In addition, a partial exfoliation of the cells is apparent. In contrast, cells migrated from the explants which had been incubated with hp-lysate $(\mathrm{HPL})(\mathrm{H})$, or with polyP (I) smoothly attach to each other and form a homogeneous margin rim of microvilli on their cell surfaces. Surface areas with extensive microvilli decorations are marked (mic).

\section{ESEM imaging}

In parallel to the light microscopical studies, ESEM inspections were performed (Fig. 5G-I). These images revealed that, according to the documentation, ${ }^{39}$ the degree of differentiation of the epithelial cells surrounding the explants is significantly different. In the controls, only occasionally strong and continuous cell-to-cell junctions are seen and only rarely prominent microvilli are formed on the cell surface (Fig. 5G). It appears that some cells already exfoliate partially. In contrast, explants incubated in medium with hp-lysate (Fig. 5H) or with polyP (Fig. 5I) show homogeneously and tightly arranged cell-to-cell borders between adjacent cells. Almost all of those cells show upright arrangements of microvilli on their cell surfaces reflecting the functional integrity of the cells.

\section{Effect of polyP on growth of the epithelial cells: proliferation assay}

The effect of polyP on the growth/viability of hCECs was assessed by the XTT-based proliferation/viability assay. The cells were cultivated in human ocular epithelia complete medium for up to $72 \mathrm{~h}$. During the total incubation period, the proliferation of the cells exposed to hp-lysate or to polyP was significantly higher compared to the controls (Fig. 6). Comparing the two groups, hp-lysate and polyP, with each other it becomes overt that the polyP-treated cultures showed a significantly higher proliferation capacity than those supplemented with hp-lysate.

\section{polyP as an inducer of gene expression}

The morphogenetic activity of polyP, induction of gene expression, has been established for vascular endothelial cells. ${ }^{40}$ Considering the outlined findings on the positive effect of the polymer on ocular epithelial cell growth and differentiation, it was advisable also to verify this potential for corneal epithelial cells. The studies were performed with hCECs that were exposed to polyP and to hp-lysate, as a comparative and likewise morphogenetic agent. Since the corneal epithelial cells migrate, proliferate and differentiate from limbal stem cells niches, the expression level of the SDF-1 chemokine appeared to be suitable as a marker gene ${ }^{41}$ to assess the niches attraction and the engraftment potential of polyP. The hCECs were incubated for 3 $\mathrm{d}$ or $6 \mathrm{~d}$ and the level of expression was determined by qRT-PCR, as described under "Material and methods". During the incubation period chosen, the steady-state-expression level in the controls became significantly upregulated after 6 d (Fig. 7). However, in the assays with hp-lysate and polyP a significant upregulation was found already after $3 \mathrm{~d}$, which further increased at day 6 to 1.9-fold and 2.9-fold, respectively, versus controls. Comparing the effects in the assays, supplemented

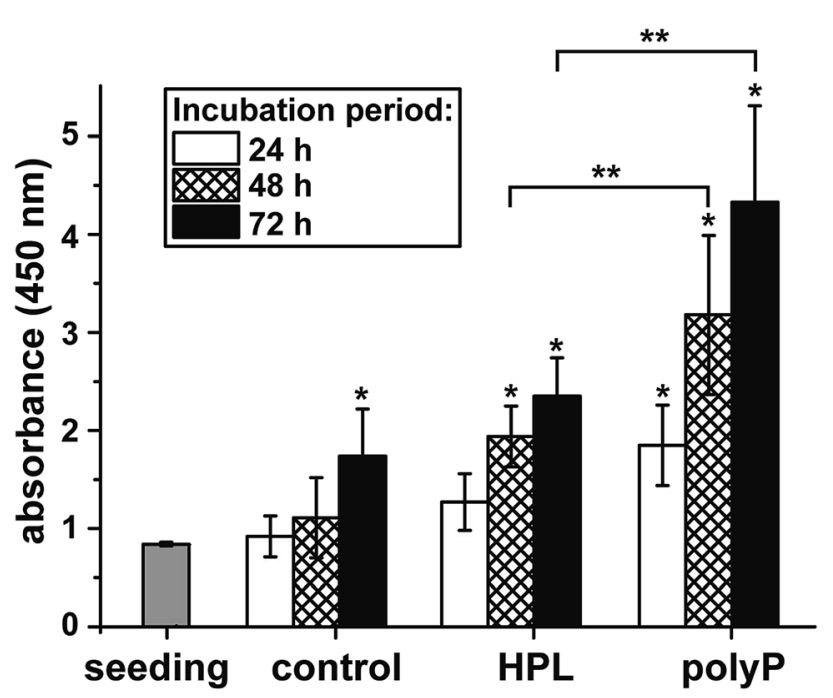

Fig. 6 Metabolic activity/growth of hCECs, growing in ocular epithelia complete medium, during a $72 \mathrm{~h}$ incubation period. Cell aliquots were taken after $24 \mathrm{~h}, 48 \mathrm{~h}$, and $72 \mathrm{~h}$ and subjected to the XTT-based proliferation/viability assay. The cultures were treated either with $5 \%$ hp-lysate (HPL) or with $50 \mu \mathrm{g} \mathrm{ml}^{-1} \mathrm{Na}$-polyP/CaCl 2 (polyP). Data represent means $\pm S D$ of ten independent experiments; the significances between the treated cultures (hp-lysate or polyP) and the respective controls are indicated with one asterisks $(*) ; P<0.01$. The significance values between the correlating treated (hp-lysate and polyP) groups are given with two asterisks $(* *)(P<0.01)$. 
with the hp-lysate or polyP, it is apparent that polyP increases the $S D F-1$ expression more potently and significantly.

\section{Discussion}

Impaired corneal regeneration remains an unresolved clinical problem in ophthalmology. In addition to lubricants, substances containing growth factors, such as autologous serum and hp-lysate, ${ }^{42}$ have been clinically applied. Studies have been performed to standardize the hp-lysate for their active bio-ingredients with some success. In the present study; we applied a frequently used concentration of $5 \% \mathrm{v} /$ $\mathrm{v}^{42}$ As a suitable concentration of polyP for the in vitro studies a range around $50 \mu \mathrm{g} \mathrm{ml}^{-1}$ has been determined. ${ }^{24}$ However, the production of such products requires logistical effort and excludes patients with certain infectious diseases. However, the main inorganic constituent of the $\mathrm{hp}$-lysate, polyP, appears to be advisable as an ingredient in eye drops. In the present study, we could attest and confirm that hp-lysate contains polyP with a chain length between 40 and $65 \mathrm{P}_{\mathrm{i}}$ units, found to be characteristic for mammalian tissue $^{9}$ and likewise being morphogenetically active (reviewed in: ref. 8); long-chain polyP with a chain length of $>200$ phosphate residues are found as depot polymers e.g. in osteoblast matrix vesicles..$^{43}$ In addition, hp-lysate is rich in ATP ${ }^{44}$ a nucleotide that is not only an essential prerequisite for platelet aggregation but also for stem cell viability and the required high metabolic energy metabolism in stem cells, including LESCs, for growth and differentiation. ${ }^{45,46}$ The beneficial effects of polyP on the metabolic function of

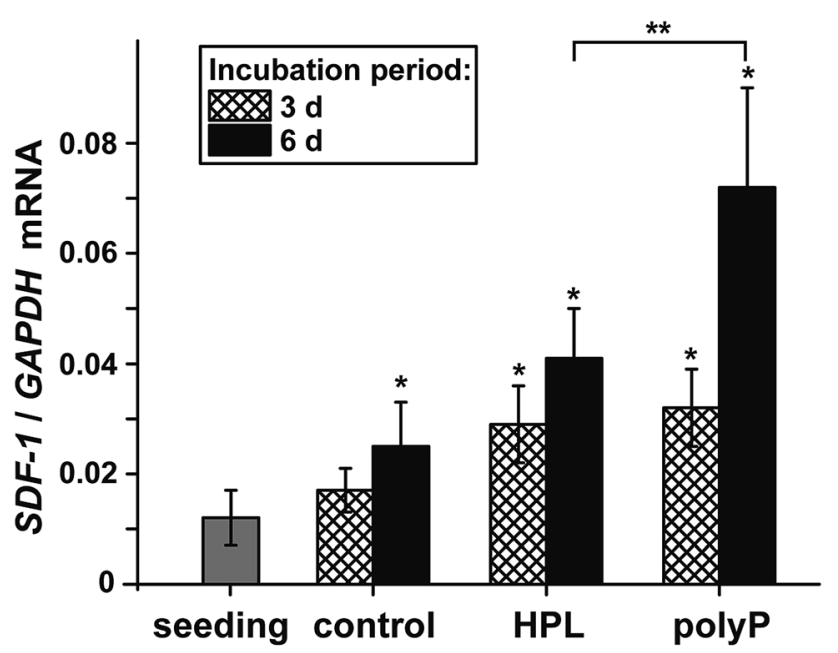

Fig. 7 Steady-state expression levels of the gene encoding for SDF-1 in untreated hCECs, compared to those incubated with $5 \%$ hp-lysate $\left(\mathrm{HPL}\right.$ ) or with $50 \mu \mathrm{g} \mathrm{ml}^{-1} \mathrm{Na}$-polyP/CaCl (polyP). After incubation for 3 $\mathrm{d}$ or $6 \mathrm{~d}$ RNA was extracted from the cells and subjected to qRT-PCR analyses. The expression values for SDF-1 were correlated to the expression of GAPDH; the respective expression ratios are given. The results are means from 5 parallel experiments. The $(*)$ significance levels to the expression values in the controls are marked $(P<0.01)$; the significance correlation between the $\mathrm{hp}$-lysate and polyP are also indicated $(* * ; P<0.01)$.

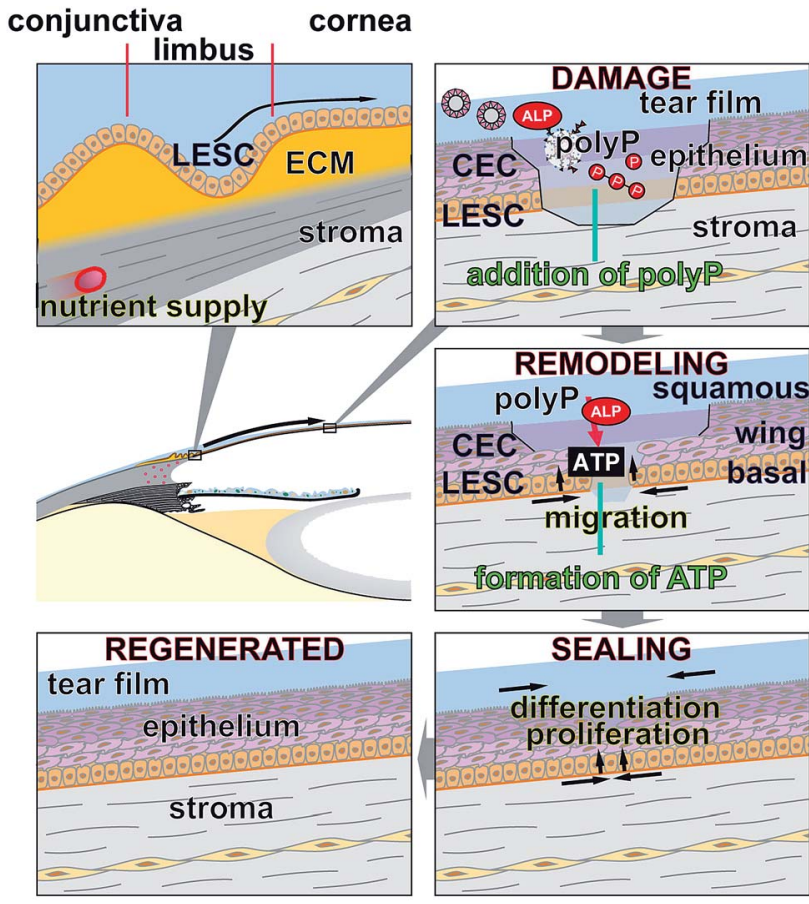

Fig. 8 Schematic outline of the repair processes proceeding at locally existing defects in the corneal epithelium. The cells which fill the damages originate from stem cells (LESC) in the limbal epithelium; at top left, only the basal layer of the limbus with the LESC without the upper layer of differentiated cells is shown. The LESCs migrate laterally in the impaired epithelium and proliferate and differentiate into the mature corneal epithelial cells (CEC) which form the basal cell-, wing cell-, and the squamous cell layers. These morphogenetic events are augmented by polyP, either existing as $\mathrm{Na}$-polyP or as polyP particles. Mediated by the ALP, which also exists in the tear fluid, extracellular ATP is formed that provides the metabolic energy for the remodeling process. It is proposed that polyP is administered as eye drops.

the epithelial cells have been proven four-fold; like a positive effect on migration, cell differentiation and cell proliferation and perhaps attraction of stem cells via increased upregulation of the SDF-1 attracting chemokine.

\section{Effect on migration}

The data summarized in the present study demonstrate that polyP is an effective component in the culture medium promoting the outgrowth of cells from limbal explants. The efficiency exceeds even the potency of hp-lysate by far. A variation of the concentrations used for the incubation of the ocular cells might even increase the strength of polyP. Even though we see this superior effect on the outgrowth of the cells already after $2 \mathrm{~d}$, it might be possible that the effect on epithelial cell migration is multiplexed by a stimulation of cell proliferation. In a first attempt to show more clearly the positive influence of polyP on migration, the cells have been co-incubated with chymase, a serine protease that inhibits the migration of corneal epithelial cells. ${ }^{38}$ This evidence supports the view that polyP promotes migration of epithelial cells and also of the existing stem cells of the corneal system. 


\section{Effect on cell differentiation}

The cells which migrated out of the explant have been proven in the present study both by immunofluorescence and by ESEM. The immunofluorescence data revealed that the epithelial cells that migrate out of the explants already form a complex multilayered cell system. Applying ESEM visualization, it became overt that the upper layer of the cells is formed by epithelial cells that are, in the absence of polyP or of hp-lysate, not intimately connected. Often cell gaps remain. However, if the cultures were treated with polyP or with hp-lysate, the corneal epithelial cells consist of regular large polygonal cells with tightly opposed cell junctions; they are covered with numerous microvilli. The tightly fitting cell junctions and the dense coverage of the cell surfaces with microvilli are the pronounced characteristics for well differentiated corneal epithelial cells. ${ }^{47}$

\section{Influence on cell proliferation}

As expected came the finding that polyP increases the proliferation rate of corneal epithelial cells. Previous studies in other cell systems already demonstrated that this polymer has a positive effect on cell growth, like for SaOS- 2 cells, ${ }^{20}$ human umbilical vein endothelial cells, ${ }^{48}$ and mesenchymal stem cells. ${ }^{49}$ We found that the amount of corneal epithelial cells growing/migrating out of the explants is substantially enhanced in the presence of hp-lysate or polyP.

\section{Expression of SDF-1}

Considering the ethical hurdles, which exist in the field of stem cell applications, an alternative could be to attract the stem cells from the surrounding tissues to the anticipated place of application. In a recent study, we could propose that polyP has the potential to attract stem cells via an increased steady-stateexpression of the gene encoding the $S D F-1$ attracting chemokine. ${ }^{8}$ Even more polyP has been found to provide a stem cell niche through transformation of the polymer to the coacervate state. ${ }^{12}$ Also, in the corneal epithelial cell system a very significant upregulation of the steady-state-expression of $S D F-1$ was measured. For the studies here we used the established human corneal epithelial cells (hCECs) between passage 3 and 8 for experiments and found that the control cultures, containing medium only, display only a slight increase in cell growth, while after addition of hp-lysate or polyP the growth rate increased by 1.4-fold to 2.5-fold. These data reflect the strong epitheliotropic effect of polyP on corneal epithelial cells.

The underlying mode of action of polyP and the distinguished property of polyP by which this polymer elicits morphogenetic activities is unique. The polymer has the propensity to be enzymatically cleaved in a processive way by the alkaline phosphatase (ALP). ${ }^{50,51}$ In each step of this enzymatic hydrolysis, a high-energy phosphoanhydride linkage is cleaved during which the stored metabolic energy is released and at least partially converted into the phosphorylation of ADT/ ATP. ${ }^{10,52}$ In turn, both the intracellular and the extracellular ATP pool increases. Subsequently, ATP/ADP have been found to act as chemotactic agents, e.g. during directed migration of human umbilical vein endothelial cells, ${ }^{53}$ or as morphogenetically active agents, e.g. by expression of a series of genes involved in anabolic cell metabolism. ${ }^{8}$ Interestingly, the cornea is rich in ALP in all three cellular layers. ${ }^{54-57}$

\section{Conclusion}

Based on the data given, the forthcoming conclusions will guide our future efforts to apply polyP in eye drops or ointments to ameliorate and relieve symptoms of corneal defects. The results of the present study revealed that polyP added into the cultivation environment to both human limbal explants and commercially available hCECs, promotes cell migration and cell growth/differentiation and also induces gene expression (Fig. 8). Hence, these data indicate that polyP may be suitable for a potential application in vivo. This indication appears to be realizable in a straightforward way, since polyP does not elicit adverse immunological reactions, is natural, and comprises supportive therapeutic advantages. The material is, as far as known today, safe and has the potential to supplement or replace eye sera. It is planned to study the biomimetical effect of polyP in the form of amorphous $\mathrm{Ca}^{2+}$ - or $\mathrm{Mg}^{2+}$-polyP nano- or micro-particles on the migration and proliferation capacity in the corneal epithelial system. Since the enzyme ALP exists also in tear fluid, it can be anticipated that in this milieu polyP, either as Na-polyP or as nano-/micro-particles, is prone to the hydrolytic attack by this enzyme, followed by a formation of metabolically useful ATP. Those particles would provide a new formulation with adjustable release kinetics not only for the epithelial cells but also for the stabilization of the mucinous layer covering these cells on the eye surface. ${ }^{58}$ In addition, this polymer would provide metabolic energy required for the regeneration of the corneal surface.

\section{Conflicts of interest}

There are no conflicts to declare.

\section{Acknowledgements}

We thank Ms. Kerstin Bahr, Institute of Functional and Clinical Anatomy, University Medical Center of the Johannes Gutenberg University, Mainz (Germany) for continuous support in cell culture and electron microscopy. This work was supported by the four ERC grants (W. E. G. M. is the holder of these four grants; an Advanced Investigator grant: grant number 268476 as well as three ERC-PoC grants: grant numbers 324564, 662486 and 767234). And this work was also supported by grants from the European Commission (grant numbers 604036 and 311848), the International Human Frontier Science Program and the BiomaTiCS research initiative of the University Medical Center Mainz.

\section{References}

1 N. Ehlers, S. Heegaard, J. Hjortdal, A. Ivarsen, K. Nielsen and J. U. Prause, Acta Ophthalmol., 2010, 88, 858-861. 
2 R. A. Thoft and J. Friend, Invest. Ophthalmol. Visual Sci., 1983, 24, 1442-1443.

3 A. Musayeva, C. Manicam, A. Steege, C. Brochhausen, B. K. Straub, K. Bell, N. Pfeiffer and A. Gericke, Am. J. Physiol.: Cell Physiol., 2018, 315, C757-C765.

4 C. Manicam, N. Perumal, J. Wasielica-Poslednik, Y. C. Ngongkole, A. Tschäbunin, M. Sievers, W. Lisch, N. Pfeiffer, F. H. Grus and A. Gericke, Sci. Rep., 2018, 8, 11526.

5 M. Haagdorens, S. I. Van Acker, V. Van Gerwen, S. Ní Dhubhghaill, C. Koppen, M. J. Tassignon and N. Zakaria, Stem Cells Int., 2016, 2016, 9798374.

6 W. E. G. Müller, E. Tolba, H. C. Schröder and X. H. Wang, Macromol. Biosci., 2015, 15, 1182-1197.

7 X. H. Wang, H. C. Schröder and W. E. G. Müller, Biotechnol. J., 2016, 11, 11-30.

8 X. H. Wang, H. C. Schröder and W. E. G. Müller, J. Mater. Chem. B, 2018, 6, 2385-2412.

9 J. H. Morrissey, S. H. Choi and S. A. Smith, Blood, 2012, 119, 5972-5979.

10 W. E. G. Müller, E. Tolba, Q. Feng, H. C. Schröder, J. S. Markl, M. Kokkinopoulou and X. H. Wang, J. Cell Sci., 2015, 128, 2202-2207.

11 W. E. G. Müller, E. Tolba, H. C. Schröder, S. Wang, G. Glaßer, R. Muñoz-Espí, T. Link and X. H. Wang, Mater. Lett., 2015, 148, 163-166.

12 W. E. G. Müller, S. Wang, E. Tolba, M. Neufurth, M. Ackermann, R. Muñoz-Espí, I. Lieberwirth, G. Glasser, H. C. Schröder and X. H. Wang, Small, 2018, 14, e1801170, DOI: $10.1002 / \mathrm{smll} .201801170$.

13 S. López-Plandolit, M. C. Morales, V. Freire, A. E. Grau and J. A. Durán, Cornea, 2011, 30, 1312-1317.

14 M. Ackermann, X. H. Wang, S. F. Wang, M. Neufurth, H. C. Schröder, F. E. Isemer and W. E. G. Müller, J. Biomed. Mater. Res., Part B, 2018, 106, 2109-2121.

15 R. Sadir, F. Baleux, A. Grosdidier, A. Imberty and H. LortatJacob, J. Biol. Chem., 2001, 276, 8288-8296.

16 A. T. Nurden, P. Nurden, M. Sanchez, I. Andia and E. Anitua, Front. Biosci., 2008, 13, 3532-3548.

17 E. Anitua, F. Muruzabal, M. de la Fuente, J. Merayo, J. Durán and G. Orive, Curr. Eye Res., 2016, 41, 875-882.

18 L. W. Chen, C. J. Huang, W. H. Tu, C. J. Lu, Y. C. Sun, S. Y. Lin and W. L. Chen, PLoS One, 2018, 13(3), e0194345.

19 Y. G. He and J. P. McCulley, Curr. Eye Res., 1991, 10, 851-863.

20 W. E. G. Müller, X. H. Wang, B. Diehl-Seifert, K. Kropf, U. Schloßmacher, I. Lieberwirth, G. Glasser, M. Wiens and H. C. Schröder, Acta Biomater., 2011, 7, 2661-2671.

$21 \mathrm{H}$. F. McMurray, D. P. Parrott and D. E. Bowyer, Atherosclerosis, 1991, 86, 227-237.

22 X. Zhou, T. Wei, C. W. Cox, A. F. Walls, Y. Jiang and W. R. Roche, Allergy, 2018, 2018, 1-11.

23 C. Mukherjee and K. Ray, An improved method for extraction and quantification of polyphosphate granules from microbial cells. Protocol Exchange (7/6/2015), p. 5, http:// www.nature.com/protocolexchange/protocols/4073.
24 X. H. Wang, M. Ackermann, E. Tolba, M. Neufurth, F. Wurm, Q. Feng, S. Wang, H. C. Schröder and W. E. G. Müller, Eur. Cells Mater., 2016, 32, 271-283.

25 J. E. Clark, H. Beegen and H. G. Wood, J. Bacteriol., 1986, 168, 1212-1219.

26 A. Giacomini, M. Ackermann, M. Belleri, D. Coltrini, B. Nico, D. Ribatti, M. A. Konerding, M. Presta and M. Righi, Angiogenesis, 2015, 18, 499-510.

27 D. F. Bray, J. Bagu and P. Koegler, Microsc. Res. Tech., 1993, 26, 489-495.

28 A. Movahedan, M. Majdi, N. Afsharkhamseh, H. M. Sagha, N. S. Saadat, K. Shalileh, B. Y. Milani, H. Ying and A. R. Djalilian, Invest. Ophthalmol. Visual Sci., 2012, 53, 7476-7483.

29 W. E. G. Müller, E. Tolba, H. C. Schröder, B. Diehl-Seifert and X. H. Wang, Eur. J. Pharm. Biopharm., 2015, 93, 214-223.

30 M. Wiens, X. H. Wang, U. Schloßmacher, I. Lieberwirth, G. Glasser, H. Ushijima, H. C. Schröder and W. E. G. Müller, Calcif. Tissue Int., 2010, 87, 513-524.

31 J. Sun, E. Nemoto, G. Hong and K. Sasaki, BMC Oral Health, 2016, 17, 26.

32 M. W. Pfaffl, Nucleic Acids Res., 2001, 29, 2002-2007.

33 A. Petrie and P. Watson, Statistics for Veterinary and Animal Science, Wiley-Blackwell, Oxford, UK, 2013, pp. 85-99.

34 J. J. Verhoef, A. D. Barendrecht, K. F. Nickel, K. Dijkxhoorn, E. Kenne, L. Labberton, O. J. McCarty, R. Schiffelers, H. F. Heijnen, A. P. Hendrickx, H. Schellekens, M. H. Fens, S. de Maat, T. Renné and C. Maas, Blood, 2017, 129, 17071717.

35 W. Li, H. He, C. L. Kuo, Y. Gao, T. Kawakita and S. C. Tseng, Invest. Ophthalmol. Visual Sci., 2006, 47, 2381-2389.

36 C. J. Huang, Y. C. Sun, K. Christopher, A. S. Pai, C. J. Lu, F. R. Hu, S. Y. Lin and W. L. Chen, PLoS One, 2017, 12, e0171008.

37 E. Tchougounova, A. Lundequist, I. Fajardo, J. O. Winberg, M. Abrink and G. Pejler, J. Biol. Chem., 2005, 280, 9291-9296.

38 N. Ebihara, T. Funaki, A. Murakami, S. Takai and M. Miyazaki, Curr. Eye Res., 2005, 30, 1061-1069.

39 B. Nichols, C. R. Dawson and B. Togni, Invest. Ophthalmol. Visual Sci., 1983, 24, 570-576.

40 W. E. G. Müller, M. Ackermann, S. F. Wang, M. Neufurth, R. Muñoz-Espí, Q. L. Feng, H. C. Schröder and X. H. Wang, Cell. Mol. Life Sci., 2018, 75, 21-32.

41 H. T. Xie, S. Y. Chen, G. G. Li and S. C. Tseng, Stem Cells, 2011, 29, 1874-1885.

42 A. Higuchi, Invest. Ophthalmol. Visual Sci., 2018, 59, DES121DES129.

43 L. Li, M. L. Khong, E. L. H. Lui, S. Mebarek, D. Magne, R. Buchet and J. A. Tanner, Biochim. Biophys. Acta, Gen. Subj., 2019, 1863, 199-209.

44 M. von Papen, S. Gambaryan, C. Schütz and J. Geiger, Transfus. Med. Hemoth., 2013, 40, 109-116.

45 J. G. Lees, D. K. Gardner and A. J. Harvey, Stem Cells Int., 2017, 2017, 2874283.

46 M. H. Frank and N. Y. Frank, Regener. Med., 2015, 10, 1-4.

47 T. Nakamura, K. Endo, L. J. Cooper, N. J. Fullwood, N. Tanifuji, M. Tsuzuki, N. Koizumi, T. Inatomi, Y. Sano 
and S. Kinoshita, Invest. Ophthalmol. Visual Sci., 2003, 44, 106-116.

48 W. E. G. Müller, S. Wang, M. Wiens, M. Neufurth, M. Ackermann, D. Relkovic, M. Kokkinopoulou, Q. Feng, H. C. Schröder and X. H. Wang, PLoS One, 2017, 12(12), e0188977.

49 E. Tolba, X. H. Wang, M. Ackermann, M. Neufurth, R. Muñoz-Espí, H. C. Schröder and W. E. G. Müller, $A d v$. Sci., 2018, 2018, 1801452.

50 B. Lorenz and H. C. Schröder, Biochim. Biophys. Acta, 2001, 1547, 254-261.

51 S. Omelon, J. Georgiou, Z. J. Henneman, L. M. Wise, B. Sukhu, T. Hunt, C. Wynnyckyj, D. Holmyard, R. Bielecki and M. D. Grynpas, PLoS One, 2009, 4, e5634.

52 W. E. G. Müller, S. Wang, M. Neufurth, M. Kokkinopoulou, Q. Feng, H. C. Schröder and X. H. Wang, J. Cell Sci., 2017, 130, 2747-2756.
53 W. E. G. Müller, M. Ackermann, E. Tolba, M. Neufurth, I. Ivetac, M. Kokkinopoulou, H. C. Schröder and X. H. Wang, Biochem. J., 2018, 475, 3255-3273.

54 Z. Lojda, J. Cejková, A. Bolková and E. Havránková, Histochemistry, 1976, 49, 237-243.

55 J. Cejková and A. Bolková, Albrecht von Graefes Arch. Klin. Exp. Ophthalmol., 1977, 204, 209-214.

56 S. L. McGowan, H. F. Edelhauser, R. R. Pfister and D. R. Whikehart, Mol. Vision, 2007, 13, 1984-2000.

57 L. F. Barba Gallardo, M. H. Muñoz Ortega, J. Ventura Juarez, L. R. Aldaba Muruato, E. Sánchez Alemán, E. E. Valdez Morales, S. S. Blancas Zugarazo and J. R. Villafan Bernal, Exp. Ther. Med., 2018, 15, 4291-4297.

58 T. Irimia, M. Ghica, L. Popa, V. Anuța, A. L. Arsene and C. E. Dinu-Pîrvu, Polymers, 2018, 10, 1221. 